Erratum

\title{
Erratum to "Effect of Thymoquinone on Acute Kidney Injury Induced by Sepsis in BALB/c Mice"
}

\author{
Li-Peng Guo, ${ }^{1}$ Si-Xu Liu, ${ }^{2}$ Qin Yang $\mathbb{D}^{2}{ }^{2}$ Hong-Yang Liu, ${ }^{3}$ Lu-Lu Xu, ${ }^{4}$ Yu-Hua Hao, ${ }^{4}$ \\ and Xiao-Qing Zhang $\mathbb{D}^{4}$ \\ ${ }^{1}$ Department of Cardiology, Dalian Third People's Hospital Affiliated to Dalian Medical University, No. 40 Qianshan Road, \\ Dalian, China \\ ${ }^{2}$ Department of Internal Medicine, Affiliated Zhongshan Hospital of Dalian University, No. 6 Jiefang Street, Dalian, China \\ ${ }^{3}$ Department of Heart Intensive Care Unit, The First Affiliated Hospital of Dalian Medical University, No. 193 Lianhe Road, \\ Dalian, China \\ ${ }^{4}$ Department of Infection, Affiliated Zhongshan Hospital of Dalian University, No. 6 Jiefang Street, Dalian, China
}

Correspondence should be addressed to Xiao-Qing Zhang; dalian0199@sina.com

Received 14 November 2020; Accepted 14 November 2020; Published 28 November 2020

Copyright (C) 2020 Li-Peng Guo et al. This is an open access article distributed under the Creative Commons Attribution License, which permits unrestricted use, distribution, and reproduction in any medium, provided the original work is properly cited.

In the article titled "Effect of Thymoquinone on Acute Kidney Injury Induced by Sepsis in BALB/c Mice" [1], Figure 1 contains an error where the image of the control group was duplicated in the image for the TQ+CLP group. This duplication was introduced during the production of the article, and the publisher apologises for this error. The corrected figure is shown below and is listed as Figure 1: 

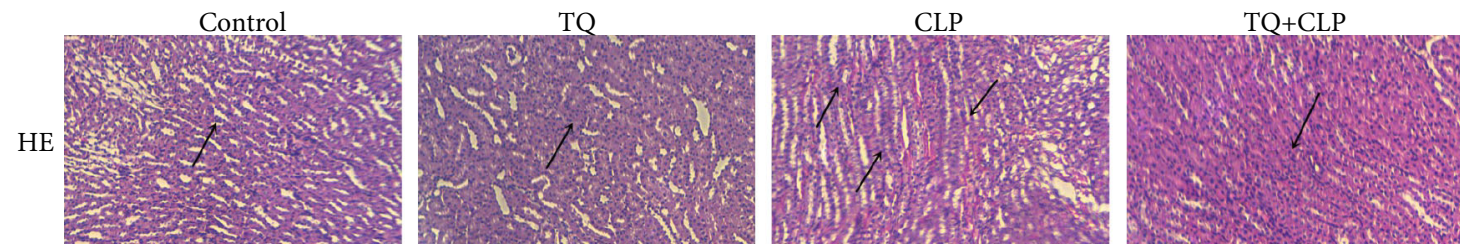

Figure 1: Inflammatory cell infiltration in kidney tissues from the BALB/c mice of the four groups with different treatments. The arrows indicated damage. Magnification 40x.

\section{References}

[1] L.-P. Guo, S.-X. Liu, Q. Yang et al., "Effect of thymoquinone on acute kidney injury induced by sepsis in BALB/c mice," BioMed Research International, vol. 2020, Article ID 1594726, 7 pages, 2020. 